\title{
Voltage Stability for a Photovoltaic System Connected to Grid by Using Genetic Algorithm Technique
}

\author{
A. Elrheem E.A. Mostafa ${ }^{1}$, Naglaa K. Bahgaat ${ }^{2}$, Mohamed Ebrahim El sayed $^{3}$ \\ and El-Said A. Othman ${ }^{4}$ \\ ${ }^{1}$ Electrical Power Eng. Dept, Faculty of Eng., Al-Azhar University, Qena, Egypt \\ ${ }^{2}$ Elec. Comm. Dept. Faculty of Eng. Canadian International College (CIC), Egypt \\ ${ }^{3,4}$ Electrical Power Eng. Dept, Faculty of Eng., Al-Azhar University, Ciro, Egypt \\ 1.rheem2017@gmail.com, ${ }^{2}$ nkbahgaat@hotmail.com, ${ }^{3}$ d_eng2009@yahoo.com, \\ 4d_2010sh@yahoo.com
}

\begin{abstract}
This paper presents an intelligent-based algorithm for voltage stability analysis of photovoltaic generation $(P V G)$ system connected to three phase utility grid for any rang of solar radiation using PI controller based Genetic Algorithm (GA) technique. Tuning the PI controller using genetic algorithms will be affected in the results of the steady state errors and the values of overhead voltages and settling times. This paper uses the MATLAB / SIMULINK software, it has been implemented for the comparison of the conventional PI controllers and the results after tuning the PI using Genetic Algorithm for photovoltaic DC voltage control it has been carried out to compare the values of settling times and overshoots voltages of each method.
\end{abstract}

Keywords: Photo Voltaic Systems, Voltage Source Converter (VSC) control, Genetic Algorithm (GA), PI controller

\section{Introduction}

There are two sorts of generating electric power from solar energy, the first type is done by converting light directly into electricity, and the second type presents by taking advantage of the sun's heat to generate electricity, such as Nevada Solar Cell power plant in Spain. At the point when the PV module are presented to daylight, they deliver coordinate current (DC) power. At that point changes over DC to AC without influencing the nature of force supply. The PV systems applications in power systems appear throw two main types as a stand-alone or off-grid applications, or as a grid -connected or ongrid applications [1]. In this paper, it was selected the grid-connected PV system because it more commonly used and widespread than off-grid, Figure 1 shows the general diagram of on-grid systems

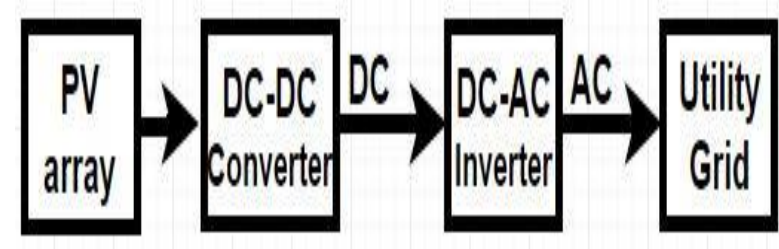

Figure 1. The General Diagram of Grid-connected PV Systems

The main components of on-grid system includes:

1) A series/parallel mixture of PV arrays to directly convert sunlight to DC power, 
2) A DC-DC converter to adjust the voltage values commensurate with inverter input,

3) An inverter to convert DC power to AC power; also keeps the PVs operating at maximum efficiency, each photovoltaic system connected to grid through a voltage source inverter $[2,3]$. The ratio of solar PV supply to power grid supply varies, depending on the size of the solar PV system. Whenever the solar PV supply exceeds the demand load, excess electricity will be exported into the grid. When there is no sunlight to generate PV electricity at night, or during abnormal weather, the power grid will supply all of the demand load [4].

The control methodology in the grid-connected inverter is a classical control problem which contains an inner current control loop and an outer voltage control loop. Figure 2 presents the block diagram of voltage sourced converter (VSC) control to control in the grid-connected PV systems, voltage loop maintains a constant voltage on the DC link capacitor and provides the reference for the inner current control loop. Also, a Phase Locked Loop (PLL) is used in order to synchronize the grid phase angle with the control system [5-7].

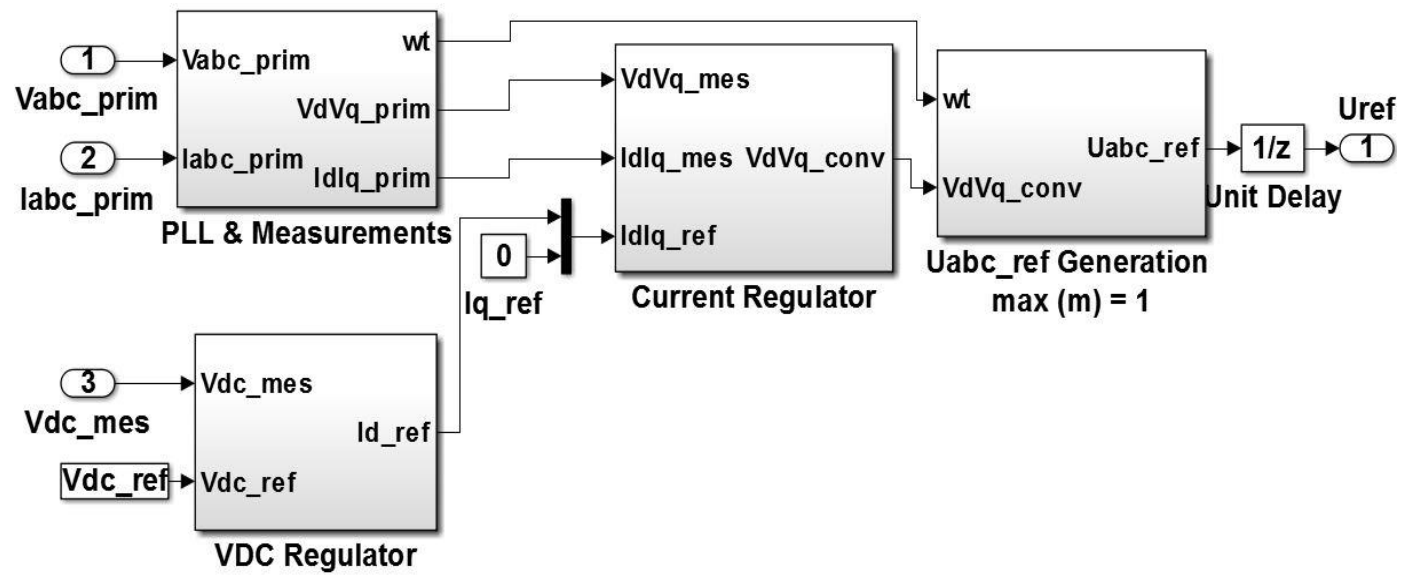

Figure 2. (VSC) Control for Grid-connected PV Systems

This paper is concerned with studying the voltage control by conventional PI controllers, and tuning PI parameters by Genetic Algorithm (GA) technique, to minimize the error of DC voltage thus make better use of the PV array, Figure 3 Shows conventional PI controller used to voltage DC regulation.

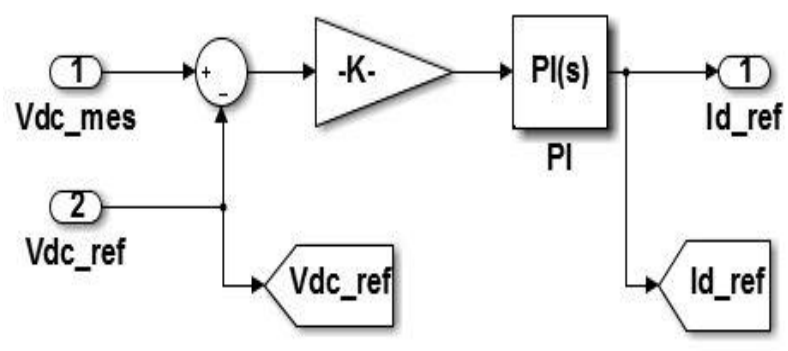

Figure 3. SIMULINK Model of Voltage Regulation by using PI Controller

\section{Genetic Algorithm (GA)}

Genetic Algorithms are search and optimization techniques inspired by two biological principles namely the process of "natural selection" and the mechanics of "natural genetics". GAs manipulate not just one potential solution to a problem but a collection of 
potential solutions. This is known as population. The potential solution in the population is called "chromosomes". These chromosomes are the encoded representations of all the parameters of the solution. Each chromosomes is compared to other chromosomes in the population and awarded fitness rating that indicates how successful this chromosomes to the latter [7-13]. There are three main stages of a genetic algorithm, these are known as reproduction, crossover and mutation [8]. The process of Genetic Algorithm will be summarized in a flow chart in Figure 4. The summary of the process will be described below.

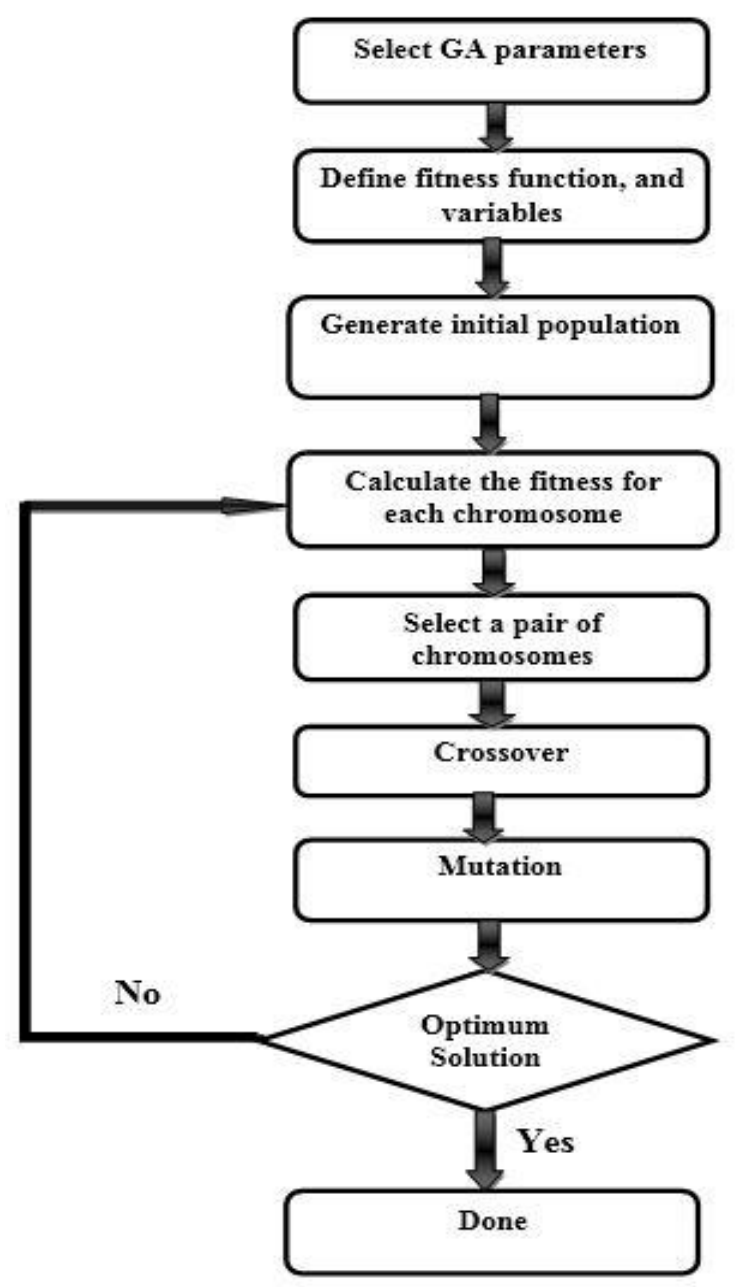

Figure 4. Genetic Algorithm Process Flowchart

The steps involved in creating and implementing a genetic algorithm:

Select GA parameters:
N The size of chromosome population
Pc The crossover probability
Pm The mutation probability
K The number of iterations
n The number of variables

1. Define fitness function $F(X)$ to measure the performance of an individual chromosome. The fitness function establishes the bases for selecting chromosomes that will be used during reproduction 
2. Generate an initial, random population of individuals for a fixed size of chromosome population $\mathbf{N}: \mathbf{X}_{1}, \mathbf{X}_{2}, \ldots . ., \mathbf{X}_{\mathbf{N}}$

3. Calculate the fitness of each individual chromosome : $\mathrm{F}\left(\mathbf{X}_{1}\right), \mathrm{F}\left(\mathbf{X}_{2}\right), \ldots . ., F\left(\mathbf{X}_{\mathbf{N}}\right)$

4. Select a pair of chromosome from the current population with a probability related to their fitness, and reproduce using a probabilistic method (e.g., roulette wheel).

5. Implement crossover operation on the reproduced chromosomes (choosing probabilistically both the crossover site and the "mates").

6. Execute mutation operation, to create a new chromosome, and place the new chromosomes in the new population, and repeat this steps until the size of the new chromosome population become equal to the size of the initial population $\mathrm{N}$.

7. Repeat steps 3 to 7 until get the optimal solution.

8. End

In this paper: by using GA to tune PI controller, the number of variables is two (KP, $\mathrm{KI}$ ), the population type is double vector, population size is 100 , the initial range of variable is $[0-1]$. For the reproduction, the crossover probability $(\mathrm{Pc})$ is 0.7 , the mutation function is Gaussian, the crossover function is scattered, the mutation probability $(\mathrm{Pm})$ is 0.001 the stopping rules is the number of generation is 100 , and the stall time limit is $6 \mathrm{sec}$.

\section{Simulation and Results}

The system which will be investigated in this paper is a 3-phase grid connected PV system as shown in Figure 5. A PV array (100-kWatt) is connected to grid (25-kVolt) via a 3-phase 3-level Voltage Source Converter (VSC) and DC-DC boost converter. This system described in [14], it consists of a) Maximum Power Point Tracking (MPPT), b) VSC, c) Phase Locked Loop (PLL), and finally d) three phase utility grid, and PV array.

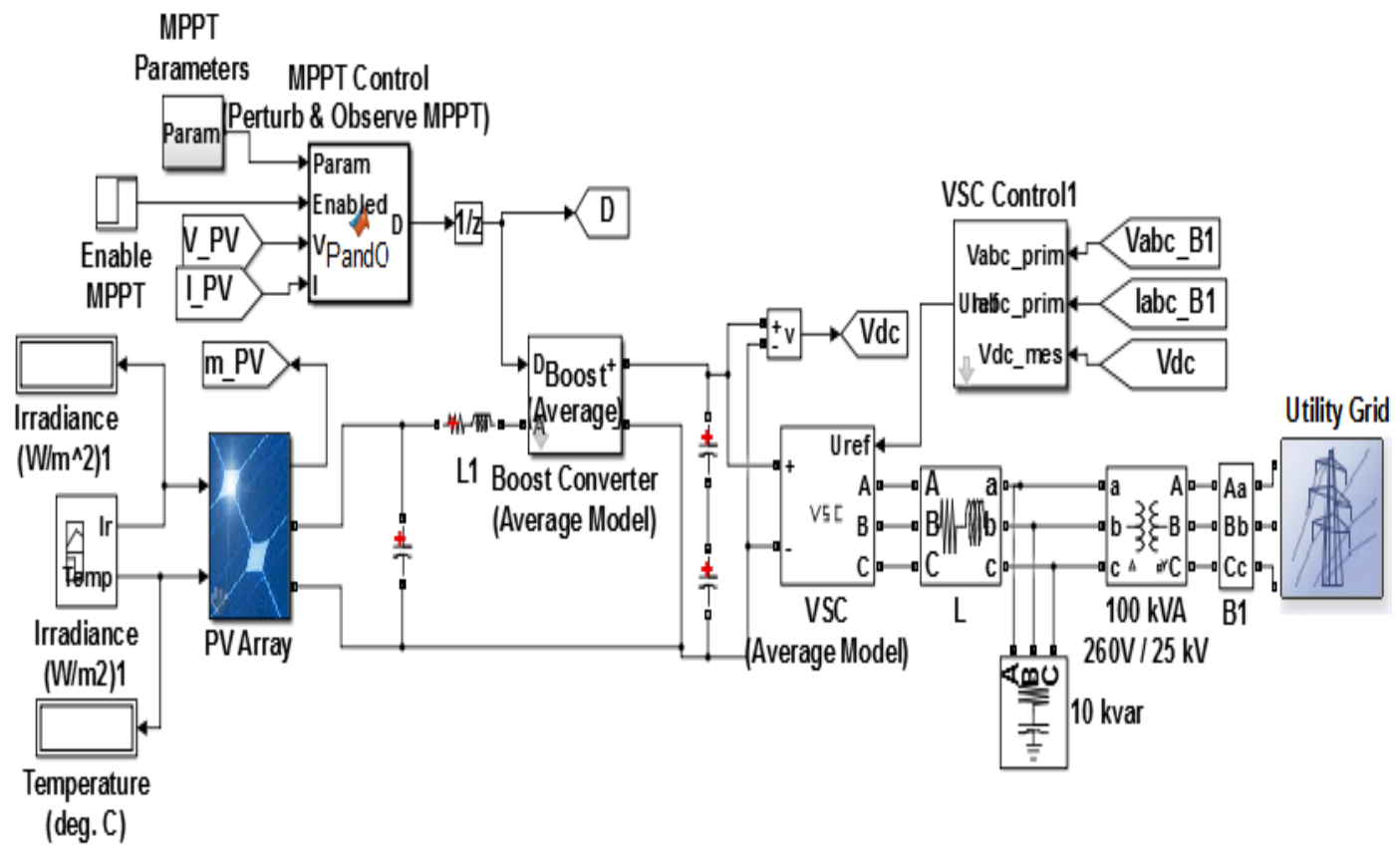

Figure 5. Three-phase Grid Connected 100kw PV System

In grid connected system, the system voltage should synchronize with the grid voltage. For this purpose, the inverter should work in the grid frequency and voltage. The control 
scheme of grid connected inverter consisting of three parts. Direct and quadrature axis current reference generator, PLL and direct and quadrature (d-q) frame generation of grid voltage and current, Conversion voltage generation, Palse Width Modulation (PWM) reference generation, Sine PWM with third harmonic injection for switching the inverter. Direct and quadrature axis current (Id-Iq) reference generation is shown in Figure 2. The dc link voltage feedback and reference dc voltage are given to Id-Iq reference generator. After making per unit the error signal is given to PI controller to produce $\mathrm{d}$ axis reference, the $\mathrm{q}$ axis component is set to be zero [14].

The grid voltage and current are given to a discrete three phase PLL to produce angle $\theta$, where $\theta=\omega t$ and $\omega$ is the utility grid fundamental frequency in the grid-connected system application. And using Park's transformation current and voltage three phase ( $a, b$, and c) are converted to (d, and q) components $[15,16]$ as shown in Figure 2.

The PV array consists of 330 Sun power modules (SPR-30E-WHT-D), the maximum power from PV array $=100.7 \mathrm{Kw}$. The manufacturer specifications for one module described in [17] are shown in Table 1. The Figure 6, and Figure 7 are shows I-V and P-V characteristics for one module and for the whole array.

Table 1. One Module Parameters of PV Array

\begin{tabular}{|l|c|}
\hline Number of cells per module & 96 \\
\hline Open circuit voltage (Voc) & $64.2 \mathrm{~V}$ \\
\hline Short circuit current (Isc) & $5.96 \mathrm{~A}$ \\
\hline voltage at maximum power (Vmp) & $54.7 \mathrm{~V}$ \\
\hline Current at maximum power (Imp) & $5.58 \mathrm{~A}$ \\
\hline
\end{tabular}

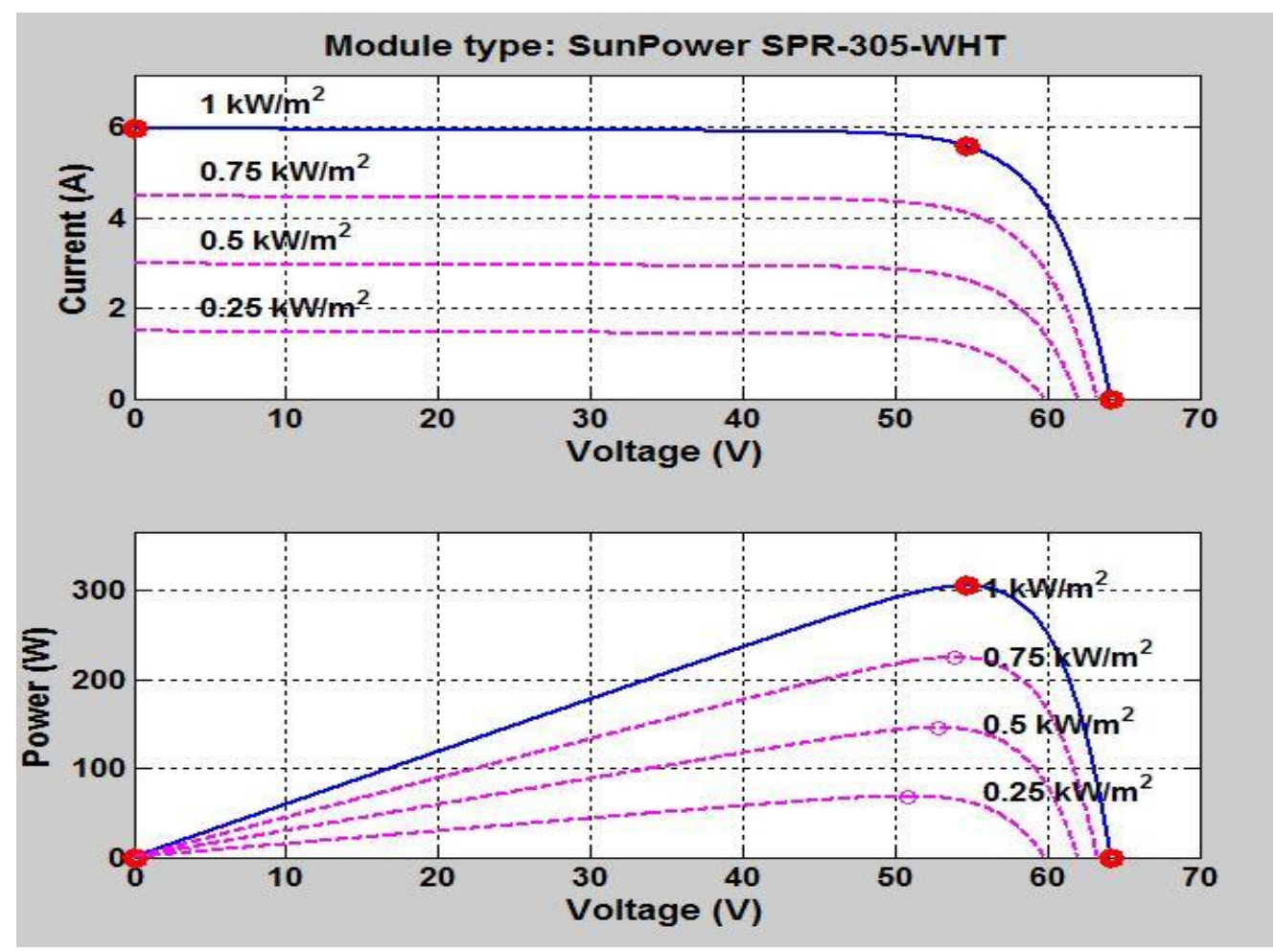

Figure 6. I-V and P-V Characteristics for One Module 


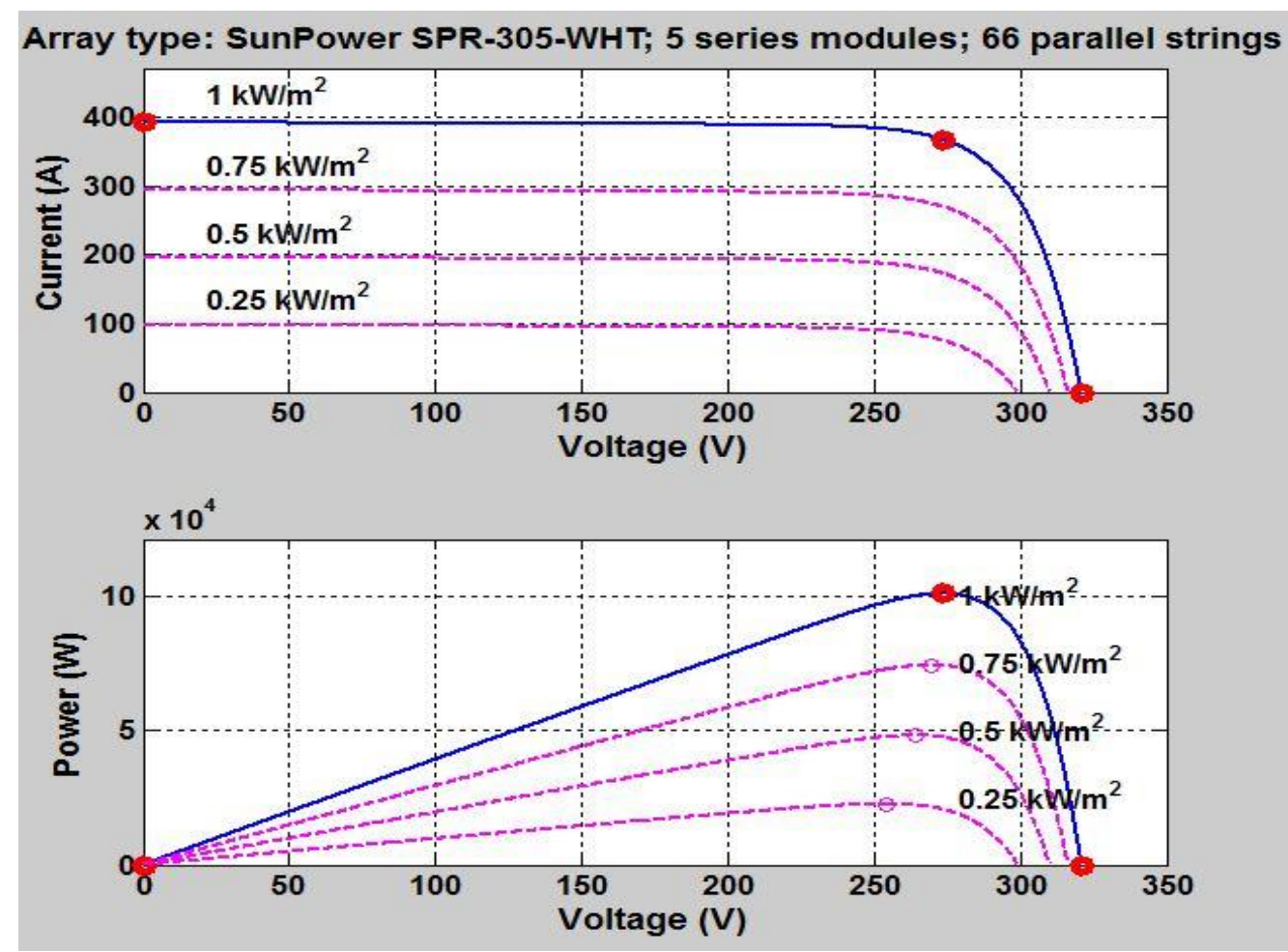

Figure 7. I-V and P-V Characteristics for Array

Voltage stability analysis of the system will study firstly without controller, and then using conventional PI controllers, and finally using tuning PI parameters by genetic algorithm technique, to minimize the error of DC voltage thus make better use of the PV array, Figure 8 Show SIMULINK model of voltage regulation by using PI controller based GA. All parameters of GA as shown in Table 2.

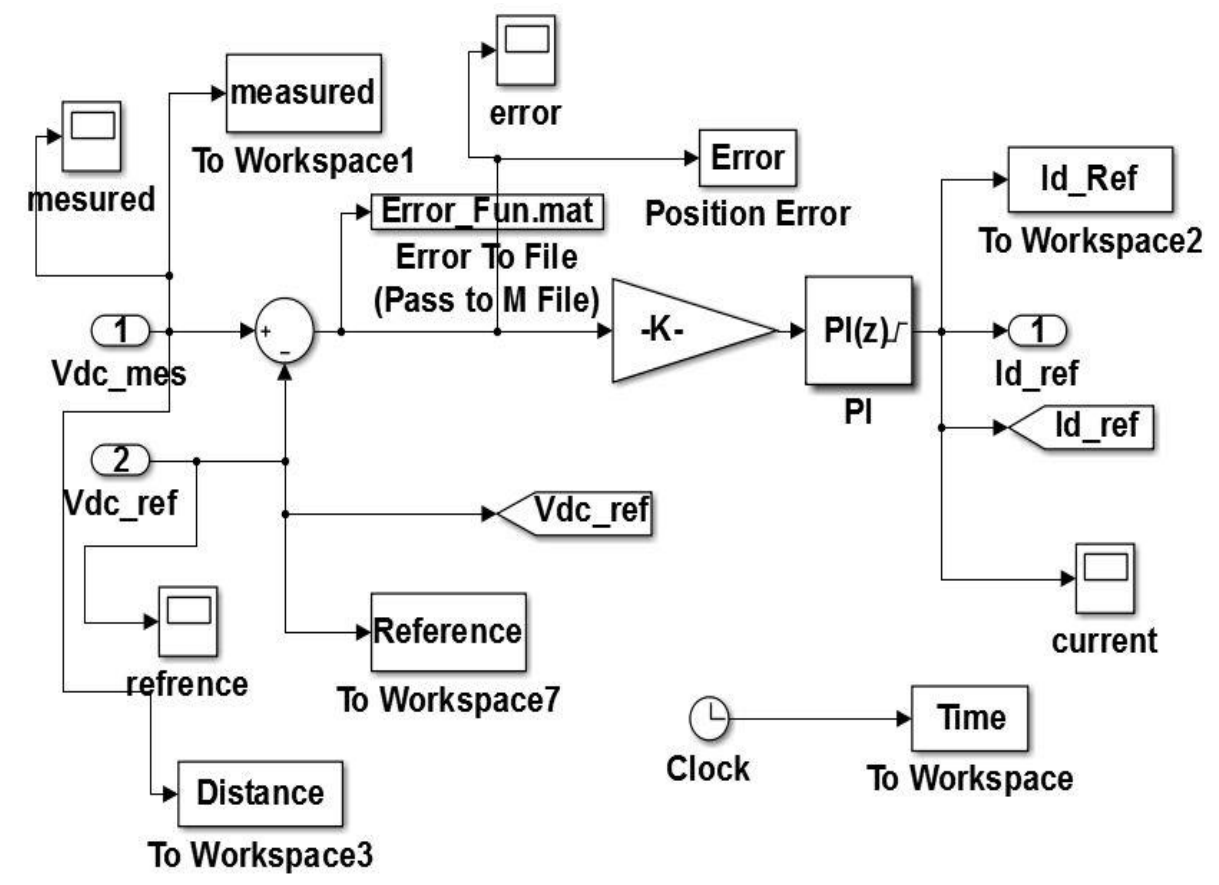

Figure 8. SIMULINK Model of Voltage Regulation by using PI Controller based GA 
Table 2. The Parameters of GA

\begin{tabular}{|l|l|}
\hline $\mathrm{K}$ & the number of iteration $=100$ \\
\hline $\mathrm{Xo}$ & The initial chromosomes position $=\left[\begin{array}{ll}1 & 0\end{array}\right]$ \\
\hline $\mathrm{Vlb}$ & The lower bounds $=\left[\begin{array}{ll}7 & 7\end{array}\right]$ \\
\hline $\mathrm{Vub}$ & The upper bounds $=\left[\begin{array}{ll}800 & 800\end{array}\right]$ \\
\hline $\mathrm{Pc}$ & The crossover probability $=0.7$ \\
\hline $\mathrm{Pm}$ & The mutation probability $=0.001$ \\
\hline
\end{tabular}

Firstly, perform simulation of the system, simulation time $=6 \mathrm{sec}$, the comparison of error of DC voltage without controller, this is shown in Figure 9.

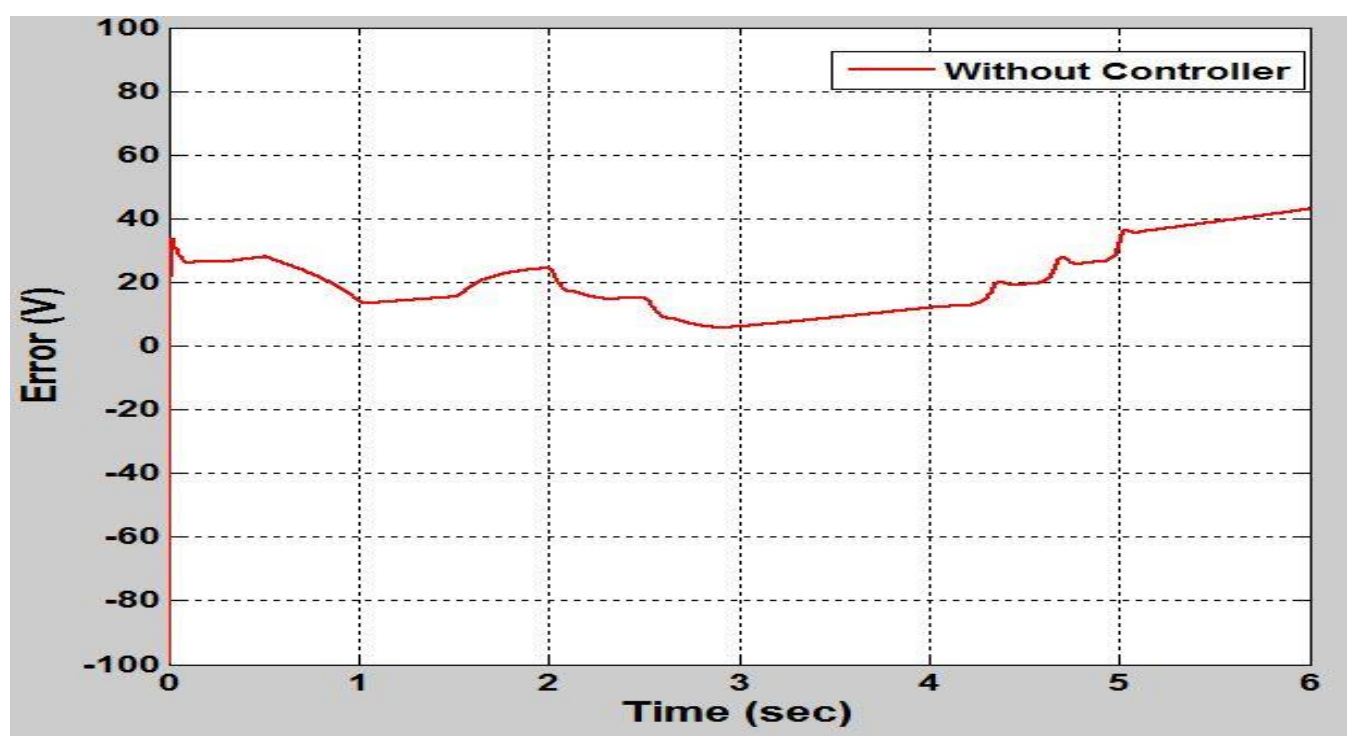

Figure 9. Error of DC Voltage without Controller

Secondly perform simulation of the system with conventional PI, the settling time and overshoot voltage with the conventional PI controllers are shown in Figure 10.

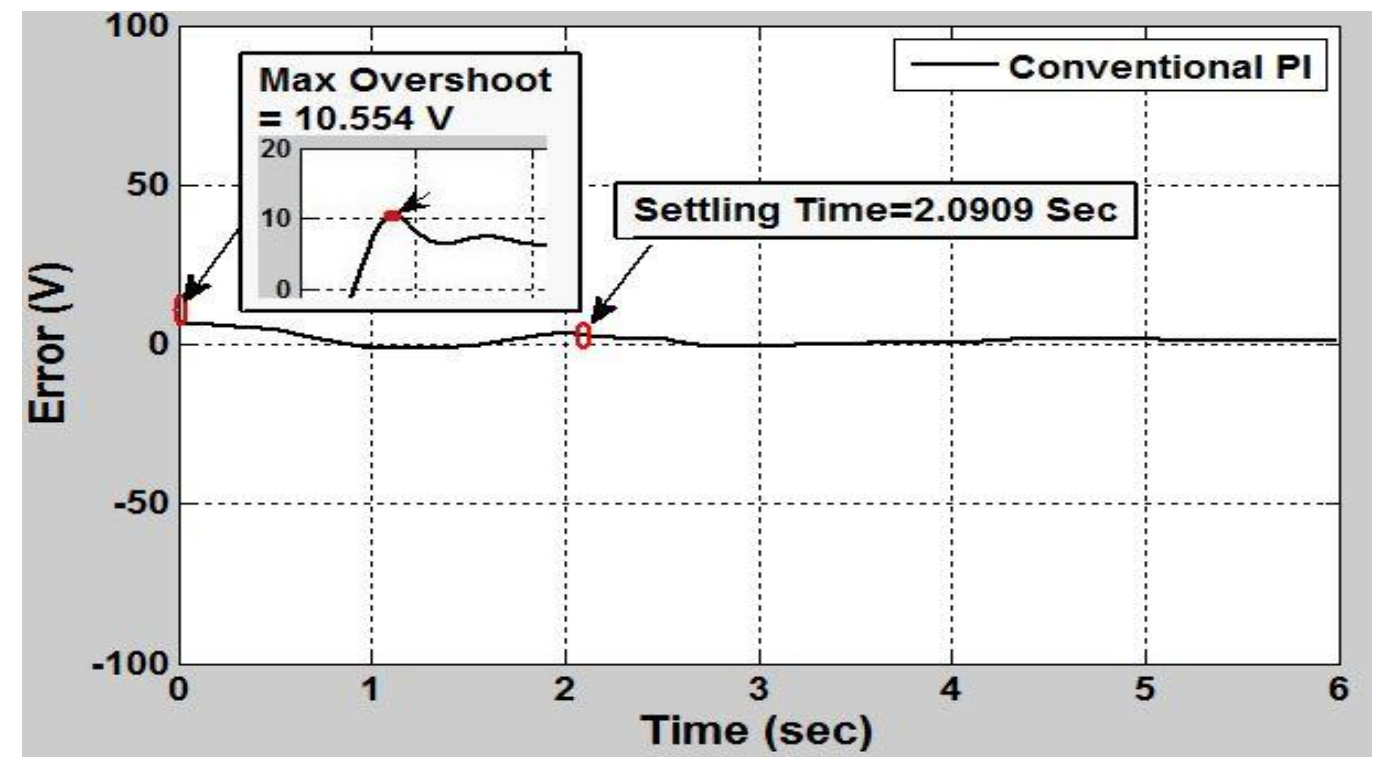

Figure 10. Error of DC Voltage with Conventional PI Controller 
Thirdly perform simulation of the system, by using PI controller based GA, writing the best results and compare the results. The top 15 results are shown in Table 3, which explains that the best result in case number 11 the settling time and overshoot voltage of the best case are shown in Figure 11.

Table 3. The Best Results of GA

\begin{tabular}{|c|c|c|c|c|c|}
\hline & $\mathrm{Kp}$ & $\mathrm{Ki}$ & Settling Time & Time at Max & Overshoot \\
\hline 1 & 125.213 & 719.891 & 0.0156 & 0.0074 & 11.6286 \\
\hline 2 & 576.957 & 706.406 & 1.5976 & 0.0073 & 9.6106 \\
\hline 3 & 104.534 & 544.568 & 0.1471 & 0.0074 & 11.151 \\
\hline 4 & 163.922 & 498.419 & 0.0155 & 0.0073 & 10.3639 \\
\hline 5 & 736.047 & 612.859 & 1.5952 & 0.0073 & 9.5931 \\
\hline 6 & 302.341 & 622.456 & 0.0261 & 0.0073 & 9.6898 \\
\hline 7 & 766.168 & 405.012 & 1.5904 & 0.0072 & 9.7141 \\
\hline 8 & 19.164 & 549.844 & 0.0616 & 0.0082 & 18.3092 \\
\hline 9 & 73.1199 & 503.109 & 0.0168 & 0.0074 & 11.5868 \\
\hline 10 & 318.233 & 307.485 & 0.0114 & 0.0073 & 9.4908 \\
\hline 11 & 287.024 & 139.263 & 0.0113 & 0.0072 & 9.1496 \\
\hline 12 & 317.961 & 764.579 & 0.026 & 0.0073 & 10.176 \\
\hline 13 & 106.797 & 770.726 & 0.0162 & 0.0075 & 12.3289 \\
\hline 14 & 158.611 & 114.777 & 0.0152 & 0.0072 & 9.1901 \\
\hline 15 & 164.735 & 491.029 & 0.0553 & 0.0073 & 10.3316 \\
\hline
\end{tabular}

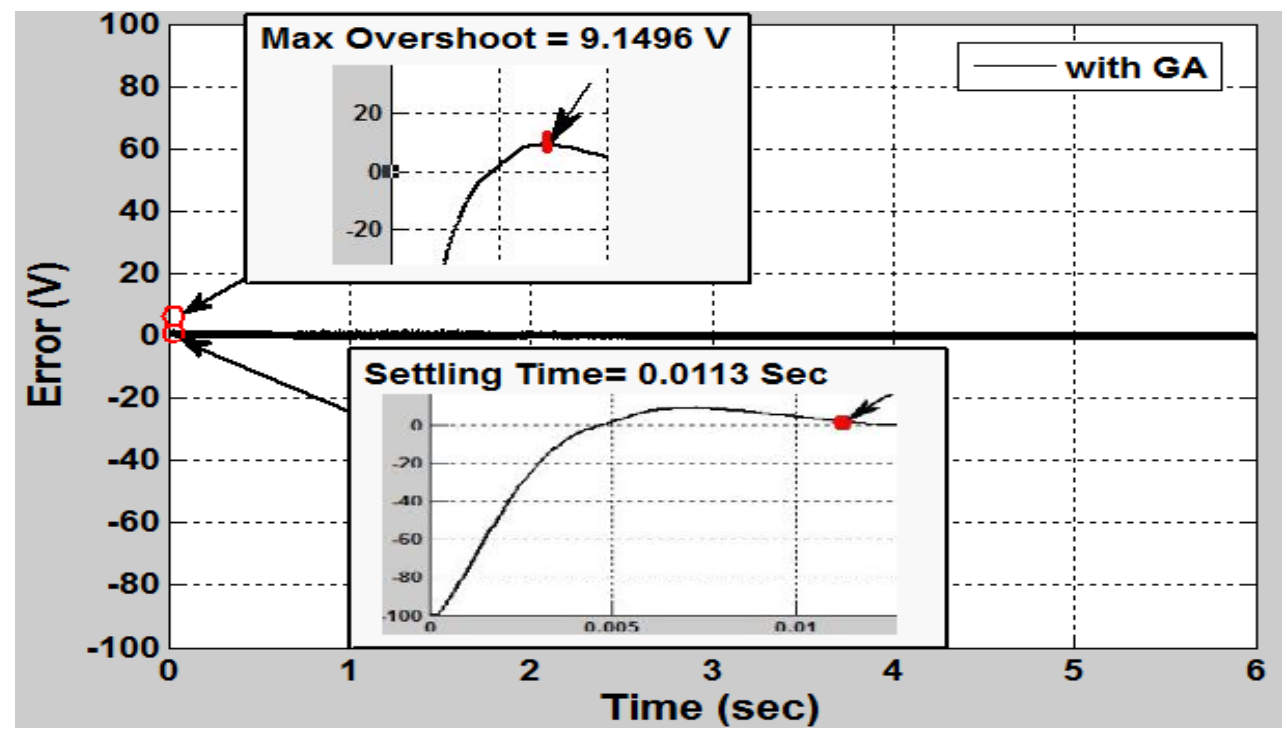

Figure 11. Error of DC Voltage with GA

Finally, a comparison between best case of GA, conventional PI, and without controller in terms of settling time and overshoot are shown in Figure 12, Figure 13 and Table 4.

Table 4. Comparison between Best Case of GA, and Conventional PI

\begin{tabular}{|l|l|l|l|l|l|}
\hline & KP & KI & Settling Time & Time at max & Overshoot \\
\hline conventional PI & 14.9830 & 12.0947 & 2.0909 & 0.0080 & 10.5540 \\
\hline PI based GA & 287.024 & 139.263 & 0.0113 & 0.0072 & 9.1496 \\
\hline
\end{tabular}




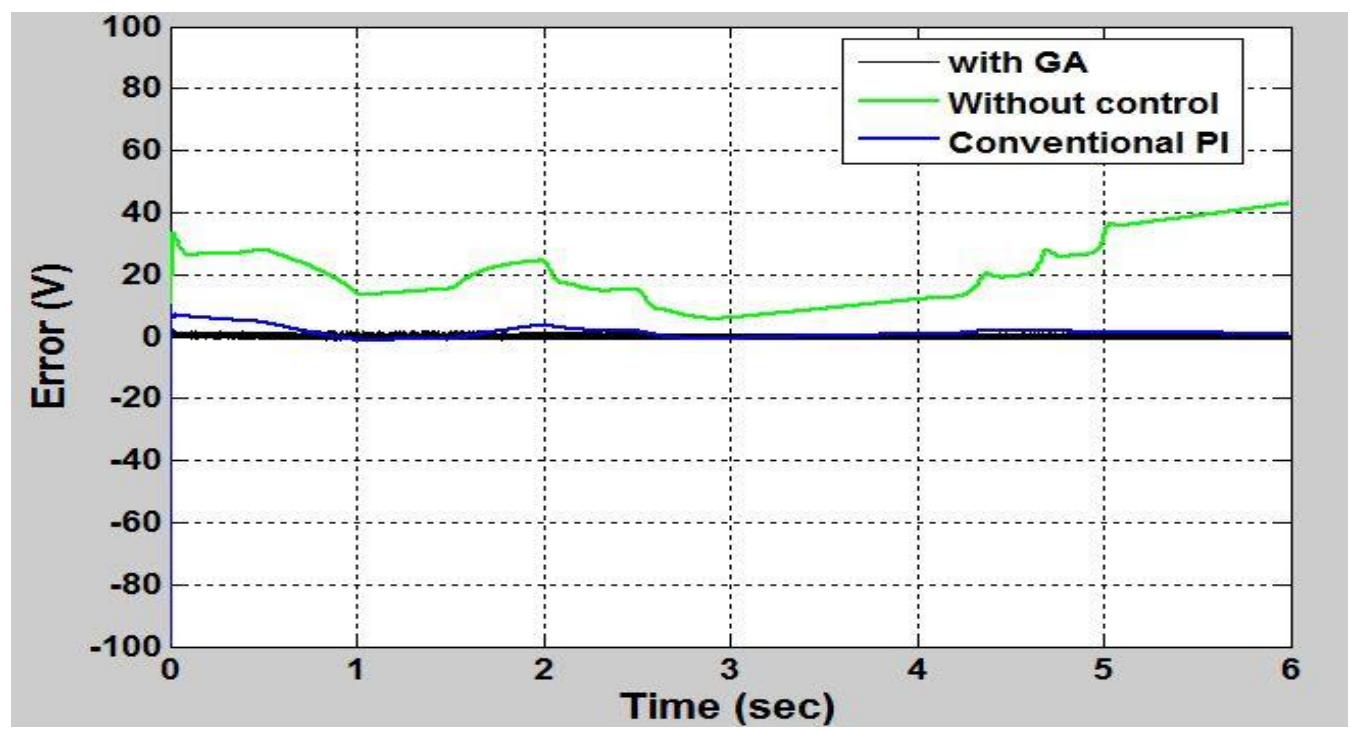

Figure 12. Comparison between Best Case of GA, Conventional PI, and without Controller

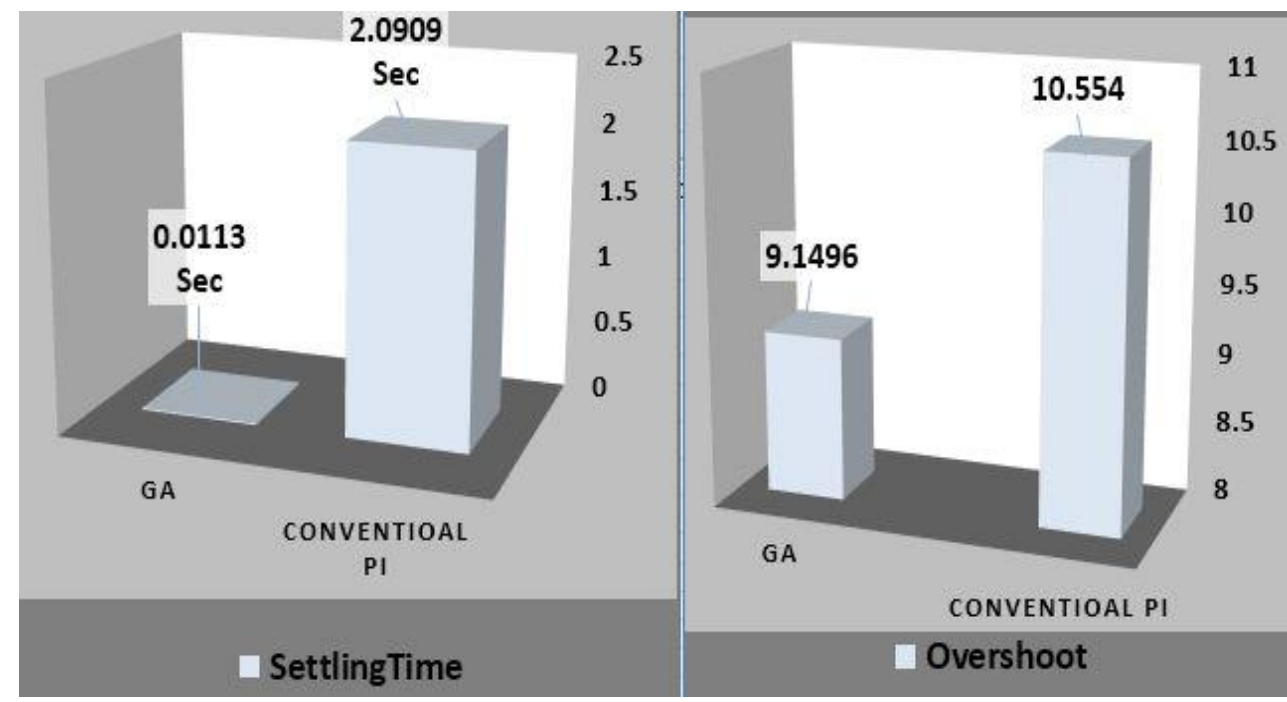

Figure 13. Comparison between Settling Times and Overshoots by Conventional PI, and GA

\section{Conclusion}

In this paper, genetic algorithm technique used for a photo-voltaic generation (PVG) system connected to three phase electrical distribution grid, the settling times and overshoot voltage values with the PI controller based genetic algorithm are compared with the results using the conventional PI controllers, the (GA) technique gives the best results, the values of the settling time and over shoot voltage are smaller than its values by using the conventional PI controller.

\section{References}

[1] S. Lakshmanan, A. Amit Jain and B. S. Rajpurohit, "An Approach to Improve Power Flow Control and Stability Analysis for Grid Connected Solar PV System”, International Conference on Circuit, Power and Computing Technologies [ICCPCT], (2015).

[2] M. A. Eltawil and Z. Zhao, "Grid-connected photovoltaic power systems: Technical and potential problems-A review", Renewable and Sustainable Energy Reviews, vol. 14, (2010), pp. 112-129. 
[3] F. Blaabjerg, Z. Chen and S. Kjaer, "Power Electronics as Efficient Interface in Dispersed Power Generation Systems", IEEE Trans. on Power Electronics, vol. 19, no. 5, (2004), pp. 1184-1194.

[4] K. Gyeong-Hun, S. Hyo-Rong, J. Seong-Jae, P. Sang-Soo, K. Sang-Yong, K. Nam-Won, P. Minwon, and Y. In-keun, "Performance analysis of the anti-islanding function of a PV-AF system under multiple PV system connections", International Conference on Electrical Machines and Systems, (2009), pp. 1-5.

[5] M. Anwari, M. I. Hamid, M. I. M. Rashid and Taufik, "Power quality analysis of grid-connected photovoltaic system with Adjustable Speed Drives", IEEE PES/IAS Conference on Sustainable Alternative Energy, (2009), pp. 1-5.

[6] W. Yi-Bo, W. Chun-Sheng, L. Hua and X. Hong-Hua, "Steadystate model and power flow analysis of grid-connected photovoltaic power system", IEEE International Conference on Industrial Technology, (2008), pp. 1-6.

[7] M. A. Tamam, "Multi objective genetic algorithm controllers Tuning for load frequency control in Electric power systems", Faculty of Engineering at Cairo University, Cairo, Egypt, (2011).

[8] H. Randy, L. Haupt and S. Ellen, "Practical Genetic Algorithms", Second Edition [Book], Hoboken, New Jersey, A John Wiley and Sons, Inc., (2004).

[9] Q. Wang, P. Spronck and R. Tracht, "An Overview Of Genetic Algorithms, Applied To Control Engineering Problems", Proceedings of the Second Conference on Machine Learning and Cybernetics, (2003).

[10] S. Gotshall and B. Rylander, "Optimal Population Size And The Genetic Algoithm", Proc On Genetic And Evolutionary Computation Conference, (2000).

[11] W. Naeem, R. Sutton, J. Chudley, F. R. Dalgleish and S. Tetlow, "An Online Genetic Algorithm Based Model Predictive Control Autopilot Design With Experimental Verification”, International Journal Of Control, vol. 78, no. 14, (2005), pp. 1076-1090.

[12] T. O’Mahony, C. J. Downing and K. Fatla, "Genetic Algorithm for PID Parameter Optimization: Minimizing Error Criteria", Process Control and Instrumentation 2000 26-28 July 2000, University of Stracthclyde, (2000), pp. 148-153.

[13] J. M. Herrero, X. Blasco, M. Martinez and J. V. Salcedo, "Optimal PID Tuning With Genetic Algorithm For Non Linear Process Models", 15th Triennial World Congress, (2002).

[14] M. Ebrahim El sayed, "Voltage Regulation for a Photovoltaic System Connected to Grid by Using a Swarm Optimization Techniques", International Journal of Scientific \& Engineering Research [IJSER], vol. 8, no. 1, (2017), pp. 33-37.

[15] S. E. Evju, "Fundamentals of grid connected photovoltaic power electronic converter design", Ph.D. dissertation, Department of Electrical Power Engineering, Norwegian University of Science and Technology.

[16] A. Timbus, M. Liserre, R. Teodorescu and F. Blaabjerg, "Synchronization methods for three phase distributed power generation systems - An overview and evaluation", Proceedings of 36th IEEE Power Electronics Specialists Conference (PESC '05), (2005), pp. 2474-2481.

[17] The 'Module' parameter of the PV Array block allows you to choose among various array types of the NREL System Advisor Model (https://sam.nrel.gov/). 